Supplement of

\title{
In situ and denuder-based measurements of elemental and reactive gaseous mercury with analysis by laser-induced fluorescence - results from the Reno Atmospheric Mercury Intercomparison Experiment
}

Anthony J. Hynes et al.

Correspondence to: Anthony J. Hynes (ahynes@ rsmas.miami.edu)

The copyright of individual parts of the supplement might differ from the CC-BY 3.0 licence. 


\section{Initial operation of the UM Tekran}

The UM Tekran was powered up after arrival at the RAMIX site and calibrated after 24 hours and again after another 24 hours. The response factors were consistent at $\sim 6 \times 10^{7}$. During this period the Tekran was sampling ambient air and was not connected to the RAMIX manifold which, as noted in the main text, was below ambient pressure. After connection to the manifold via $25 \mathrm{ft}$ of 0.25 inch tubing, an external pump was connected to allow the instrument to maintain a $1.5 \mathrm{~L} \mathrm{~min}^{-1}$ sampling rate. At hour 72 on August $29^{\text {th }}$ the Tekran was recalibrated and the response factor dropped to $\sim 4.3 \times 10^{7}$. At the next recalibration on September $2^{\text {nd }}$ at hour 175 the response factor increased to $\sim 6 \times 10^{7}$ and

then on September $7^{\text {th }}$ decreased to $\sim 4.5 \times 10^{7}$. In addition to the instability in the response factors there was some instability in overall response that was not related to calibration. After sampling began from the manifold at hour zero, which corresponds to 9 am on August $26^{\text {th }}$, the UM Tekran was offset by $\sim+0.5 \mathrm{ng} \mathrm{m}^{-3}$ with respect to the UNR Tekran and this offset increased to $\sim+2 \mathrm{ng} \mathrm{m}^{-3}$ at hour 30 on August $27^{\text {th }}$. This increase in offset occurred after the UM system was disconnected from the manifold and flushed with the $\mathrm{N}_{2}$ blowoff from a liquid nitrogen tank that gave good zeros but would have increased the pressure in the system to ambient pressure. The large offset is caused by the UM instrument reading high and the UNR instrument reading low and then over the next 45 hours the instruments converge. This instability occurred prior to any manifold spiking with $\mathrm{HgBr}_{2}$. As noted in Section 3.2 of the manuscript, our focus during this initial period of the intercomparison was on the two laser systems that were being set up. We are unable to identify the reasons for these problems which may have been associated with the use of an external pump to supplement the internal Tekran pump, or with the fact that the instrument had been powered down for almost one week and relocated to a site at a significantly different ambient pressure. In retrospect we can acknowledge that greater attention should have been paid to quality assurance with the UM Tekran. We conclude that the difference between the UM and UNR instruments is an experimental artifact.

\section{Can any currently identified chemistry rationalize the RAMIX results?}


As we noted in the manuscript, attempts to rationalize the discrepancies in the RAMIX dataset using any currently identified chemistry are extremely problematic. This is particularly the case for the reactions of $\mathrm{Hg}(0)$ with $\mathrm{NO}_{3}$ and $\mathrm{O}_{3}$ that are suggested by Ambrose et al. (2013) as a potential mechanism for the high RGM concentrations measured by the DOGHS instrument. We have discussed these reactions in detail (Hynes et al., 2009) and we would suggest that more recent work confirms our conclusions. Any hypothesized oxidation chemistry for $\mathrm{Hg}(0)$ is constrained by the fact that the $\mathrm{HgO}$ molecule is very weakly bound (Shepler and Peterson, 2003). Taking the binding energy of $17 \mathrm{~kJ} /$ mole calculated by Shepler and Peterson (2003) makes an abstraction reaction of $\mathrm{Hg}(0)$ with $\mathrm{NO}_{3}$ endoergic by $195 \mathrm{~kJ} / \mathrm{mol}$.

$$
\mathrm{Hg}+\mathrm{NO}_{3}->\mathrm{HgO}+\mathrm{NO}_{2} \quad \Delta \mathrm{H}^{0}=195 \mathrm{~kJ} / \mathrm{mol}
$$

Recent work by Dibble et al. (2012) calculated a binding energy of $21 \mathrm{~kJ} / \mathrm{mol}$ for an Hg$\mathrm{NO}_{3}$ adduct, suggesting that any such adduct would be too short lived to undergo further reaction.

Measurements of the reaction of $\mathrm{Hg}(0)$ with ozone have recently been reported by Rutter et al. (2012). They reported two experiments in which they monitored the decay of $\mathrm{Hg}(0)$ in a large excess of ozone.

Fig 1a) $\left[\mathrm{O}_{3}\right]: 1.2 \times 10^{13}$ molecules $\mathrm{cm}^{-3},[\mathrm{Hg}(0)]: 10.7 \mathrm{ng} \mathrm{m}^{-3}: 3.2 \times 10^{7}$ atoms cm ${ }^{-3}$ Fig $1 b)\left[\mathrm{O}_{3}\right]: 6.5 \times 10^{12}$ molecules $\mathrm{cm}^{-3},[\mathrm{Hg}(0)]: 75.5 \mathrm{ng} \mathrm{m}^{-3}: 2.3 \times 10^{8}$ atoms $\mathrm{cm}^{-3}$

If the reaction can be treated as a simple gas phase bimolecular reaction with reactants proceeding to products, i.e. any reverse reaction can be ignored, and one reactant is in large excess then the reaction proceeds under pseudo-first order conditions. Since the ozone concentration is in large excess it remains essentially constant, hence the $\operatorname{Hg}(0)$ concentration should decay exponentially and a plot of $\ln [\mathrm{Hg}(0)]$ vs time should be linear and give a pseudo-first order decay rate, k'. A plot of k' vs the excess reactant, ozone, should then give a bimolecular rate coefficient. Typically, if a reaction shows good pseudo-first order behavior the decaying reactant will show an exponential decay for 3 $1 / \mathrm{e}$ times. This means that it will decay exponentially until the concentration is $\sim 5 \%$ of the initial concentration. Deviations from this behavior are a clear indication that it is not 
possible to treat the reaction as a simple bimolecular process. In the Rutter et al. (2012) study the authors noted that:

"After the first $1.4 \mathrm{~h}$ a divergence from the model was observed in which the net oxidation was decreased with respect to the model predictions. Data collected after this point became inconsistent and tended to show a decreased net oxidation, or even reduction-like behavior, at a variety of experimental times. Such behavior was also observed after $1.4 \mathrm{~h}$ in the GEM-ozone experiments. No definitive explanation is available, but all data collected after $1.4 \mathrm{~h}$ are considered unreliable due to potential artifacts."

The model referred to here is simply pseudo-first order behavior for the $\mathrm{Hg}(0)$-ozone experiments. Rutter et al. (2012) obtained rate coefficients based on $\mathrm{Hg}(0)$ concentrations that had decayed to $98 \%$ and $96 \%$ of their original concentration and then acknowledge that the decays deviate from pseudo-first order behavior. This is a very clear indication that the ozone- $\operatorname{Hg}(0)$ reaction cannot be treated as pseudo-first order. It seems clear that ozone and $\operatorname{Hg}(0)$ react slowly on surfaces and we have observed such a reaction in our laboratory. A slow wall reaction of ozone with $\operatorname{Hg}(0)$ could explain the slow decay rates initially observed by Rutter et al. (2012). There is no evidence that heterogeneouslymediated oxidation of ozone occurs in the atmosphere but if it does a much more complicated formulism would be required to treat the process as described by Poschl et al. (2007).

\section{Supplementary References:}

Ambrose, J. L.; Lyman, S. N.; Huang, J.; Gustin, M. S.; Jaffe, D. A.: Fast time resolution oxidized mercury measurements during the Reno Atmospheric Mercury Intercomparison Experiment (RAMIX). Environ. Sci. Technol. 47, 7284-7294; DOI 10.1021/es303916v, 2013

Dibble, T. S., Zelie, M. J., and Mao, H.: Thermodynamics of reactions of $\mathrm{ClHg}$ and $\mathrm{BrHg}$ radicals with atmospherically abundant free radicals, Atmos. Chem. Phys., 12, 1027110279, doi:10.5194/acp-12-10271-2012, 2012. 
Hynes, A. J.; Donohoue, D. L.; Goodsite, M. E.; Hedgecock, I. M., Our current understanding of major chemical and physical processes affecting mercury dynamics in the atmosphere and at the air-water/terrestrial interfaces In Mercury Fate and Transport in the Global Atmosphere, Mason, R.; Pirrone, N., Eds. Spring New York, NY, 2009.

Poschl, U., Rudich, Y., and Ammann, M.: Kinetic model framework for aerosol and cloud surface chemistry and gas-particle interactions - Part 1: General equations, parameters, and terminology, Atmos. Chem. Phys., 7, 5989-6023, 2007.

Rutter, A.P., Shakya, K.M., Lehr, R., Schauer, J. J., Griffin, R. J., Oxidation of gaseous elemental mercury in the presence of secondary organic aerosols, Atmos. Environ., 59, 86-92, 2012.

Shepler, B. C.; Peterson, K. A.: Mercury monoxide: A systematic investigation of its ground electronic state, J. Phys. Chem., A, 107, 1783, 2003.

\section{Supplementary Figures}




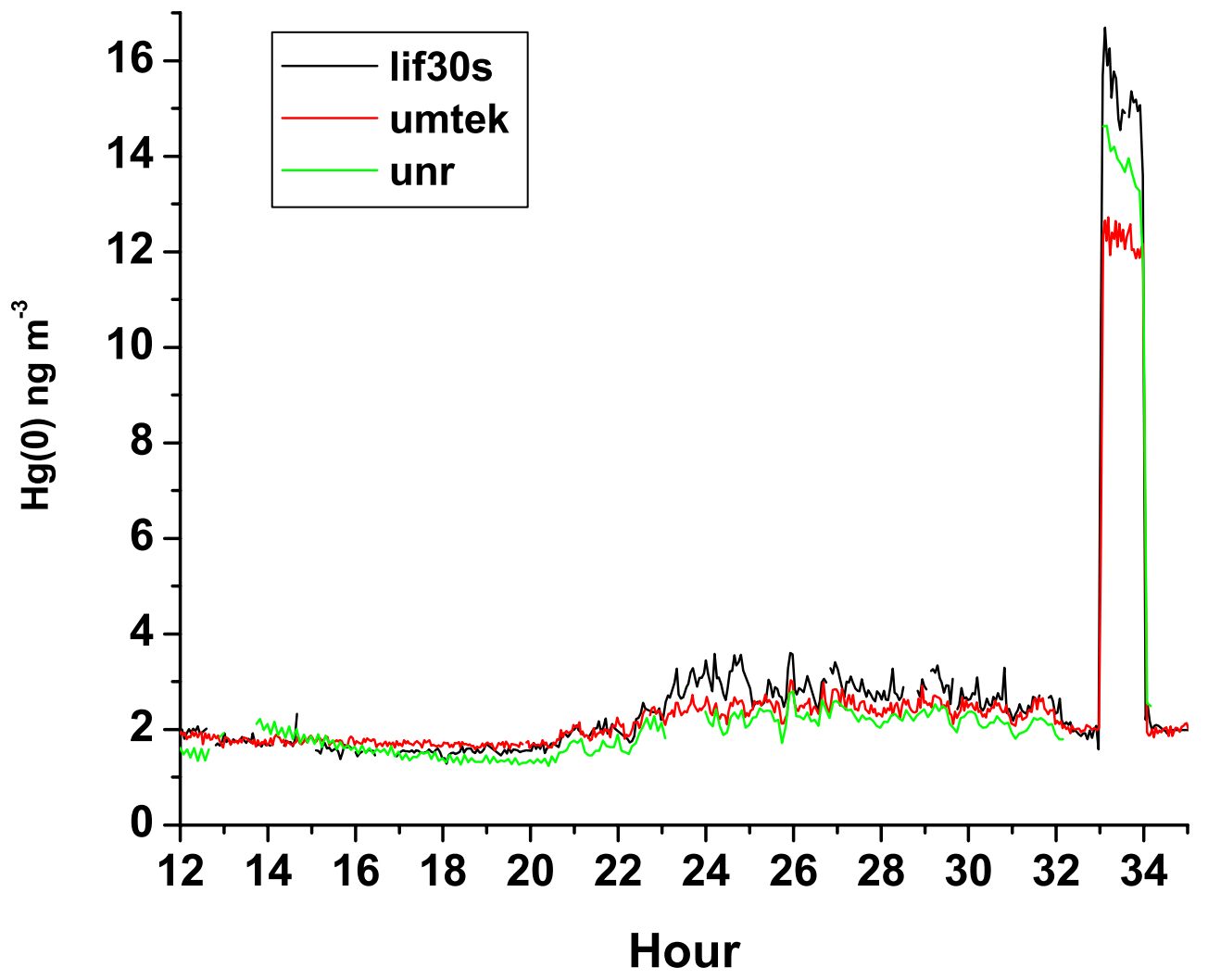

SI Figure 1: 22 hour sampling period from September $1^{\text {st }}$ and $2^{\text {nd }}$. Comparison of the UM (red line) and UNR (green line) Tekrans with the UM 2P-LIF (black line) concentrations. The UM 2P-LIF signal was calibrated from the UM Tekran concentrations at the beginning of hour 13 . 


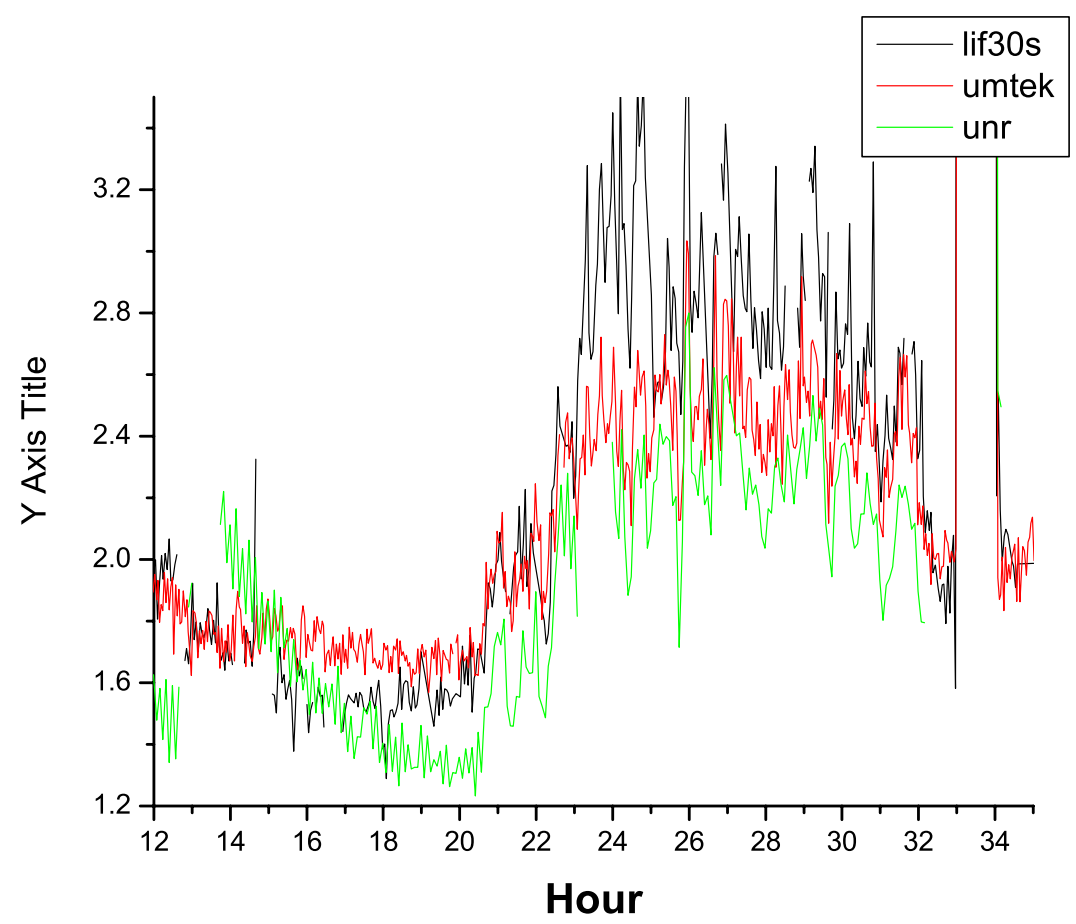

SI Figure 2: This is the same dataset as in Fig. 1 with an expanded concentration scale focusing on ambient measurements.

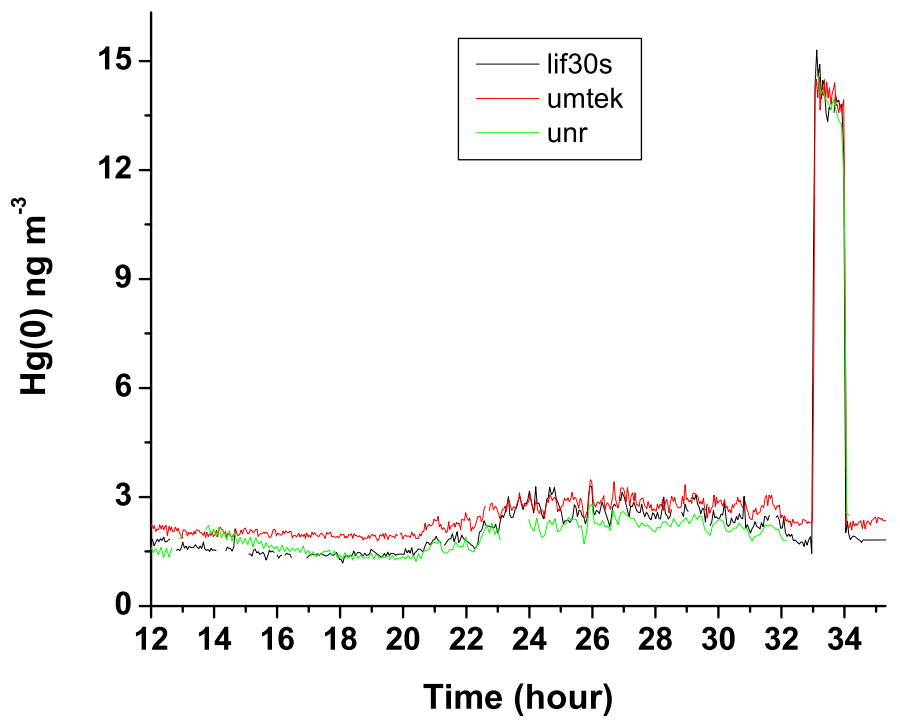


SI Figure 3: 22 hour sampling period from September $1^{\text {st }}$ and $2^{\text {nd }}$. Comparison of the UM (black line) and UNR (green line) Tekrans with the UM 2P-LIF (black line) concentrations. The UM Tekran and UM 2P-LIF instruments were calibrated by the UNR Tekran concentration at the beginning of hour 33, i.e. all instruments were normalized to the second manifold spike at hour 33

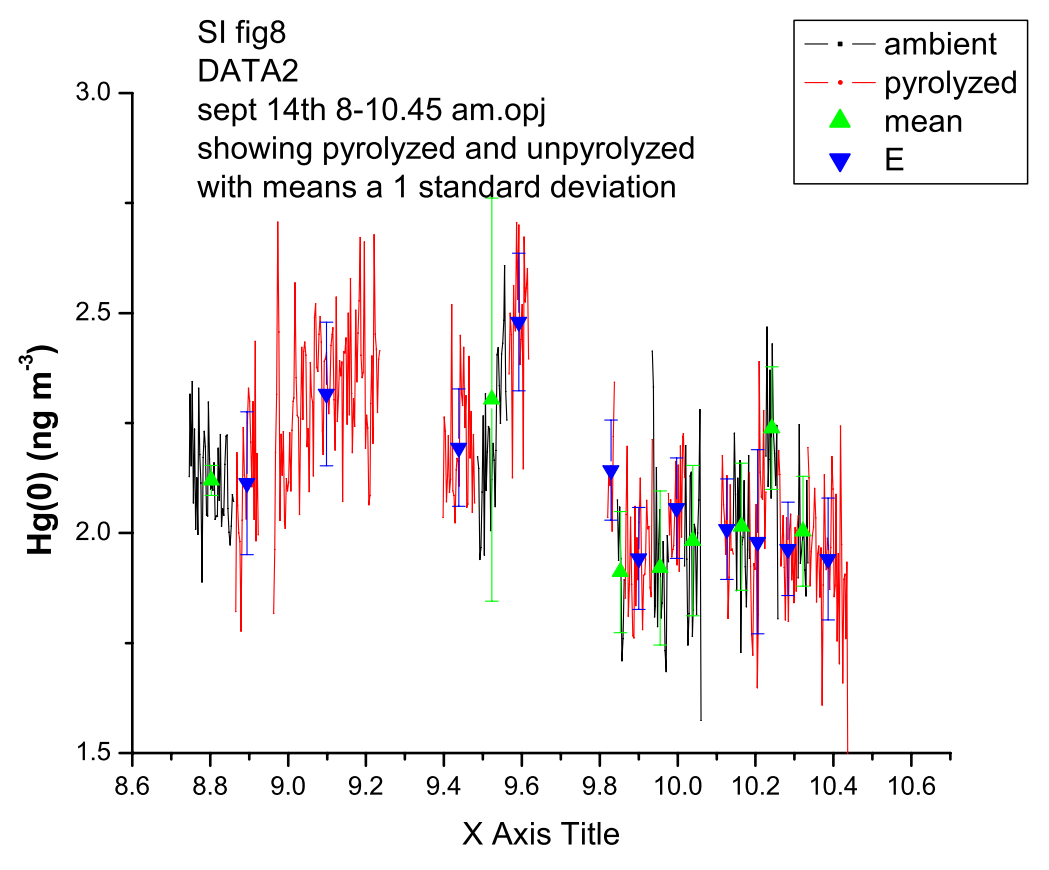

SI Figure 4: September 14 measurements 8-10.45 am. The background subtracted 2PLIF signals from the ambient channel (black) and pyrolyzed channel (red) are shown. The gaps correspond to times when the laser was blocked to check power and background. The means and 1 standard deviation are shown. 


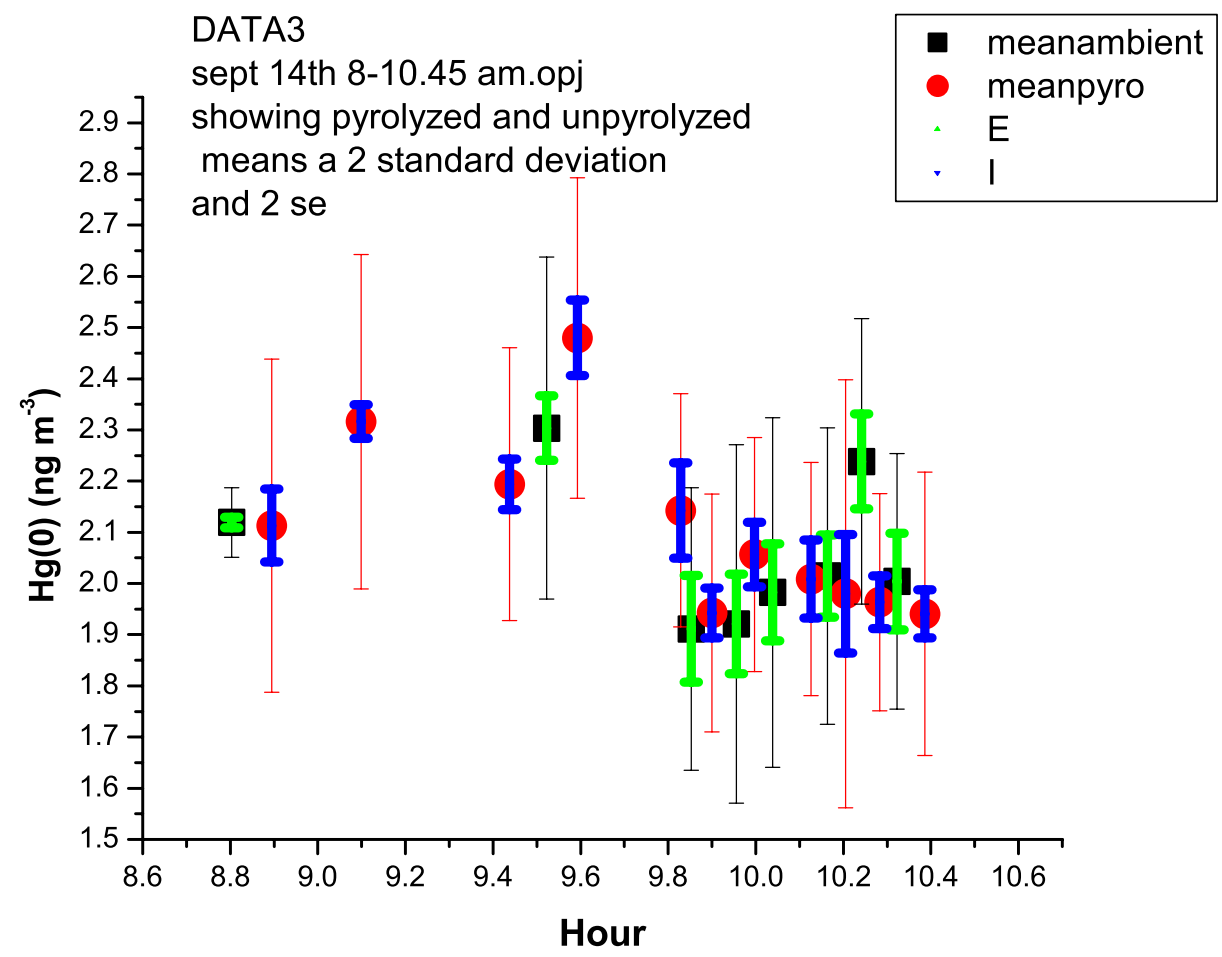

SI Figure 5: September 14 measurements 8-10.45 am. The means of the ambient channel (black) and pyrolyzed channel (red) are shown. The error bars show both 2 standard errors (thicker line) and 2 standard deviations. 


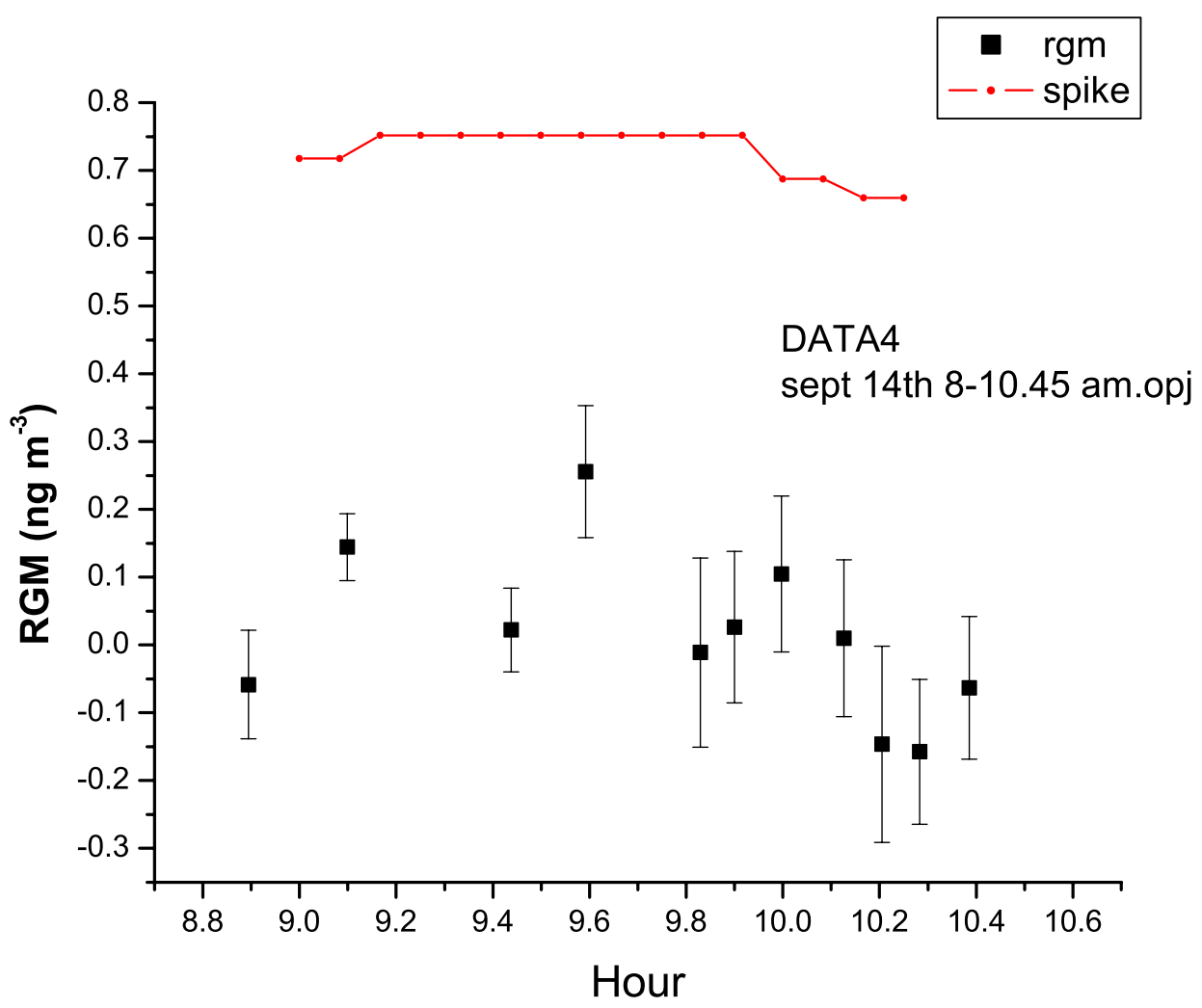

SI Figure 6: September 14 measurements 8-10.45 am. The RGM concentration obtained from the difference between the pyrolyzed and ambient $\mathrm{Hg}(0)$ concentrations is shown. The error bars show 2 standard errors. 


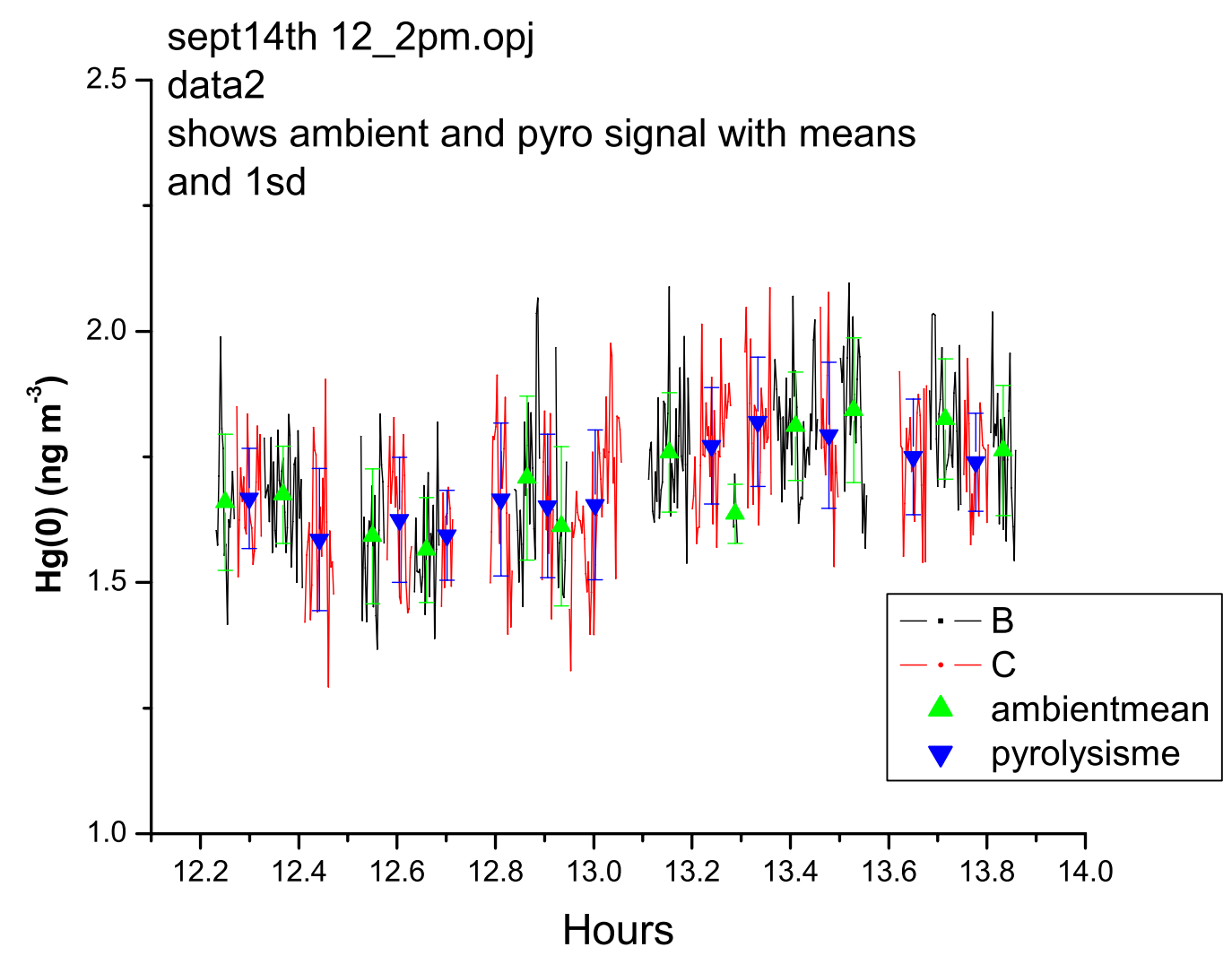

SI Figure 7: September 14 measurements 12-2pm. The background subtracted 2P-LIF signals from the ambient channel (black) and pyrolyzed channel (red) are shown. The gaps correspond to times when the laser was blocked to check power and background. The means and 1 standard deviation are shown. 


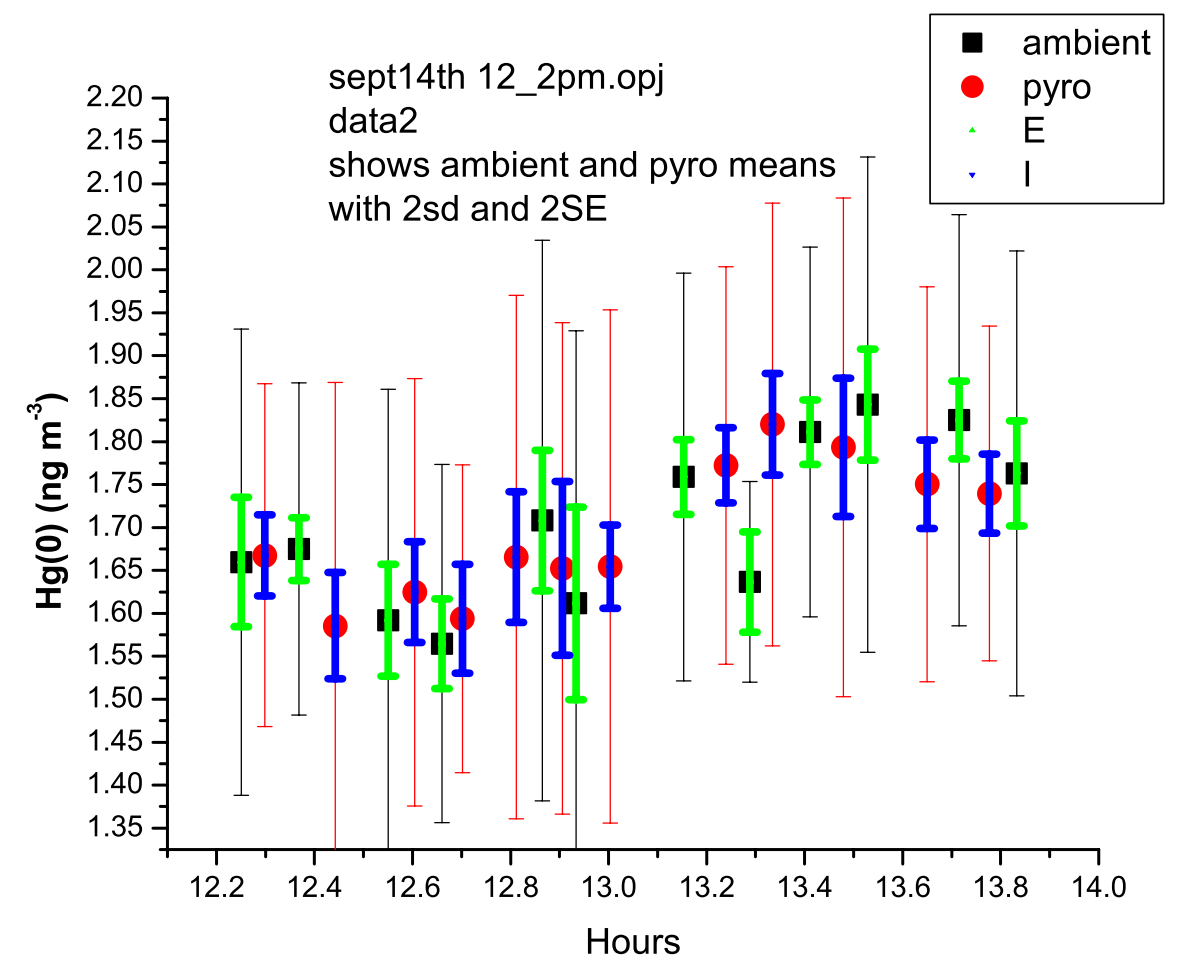

SI Figure 8: September 14 measurements $12-2 \mathrm{pm}$. The means of the ambient channel (black) and pyrolyzed channel (red) are shown. The error bars show both 2 standard errors (thicker line) and 2 standard deviations. 


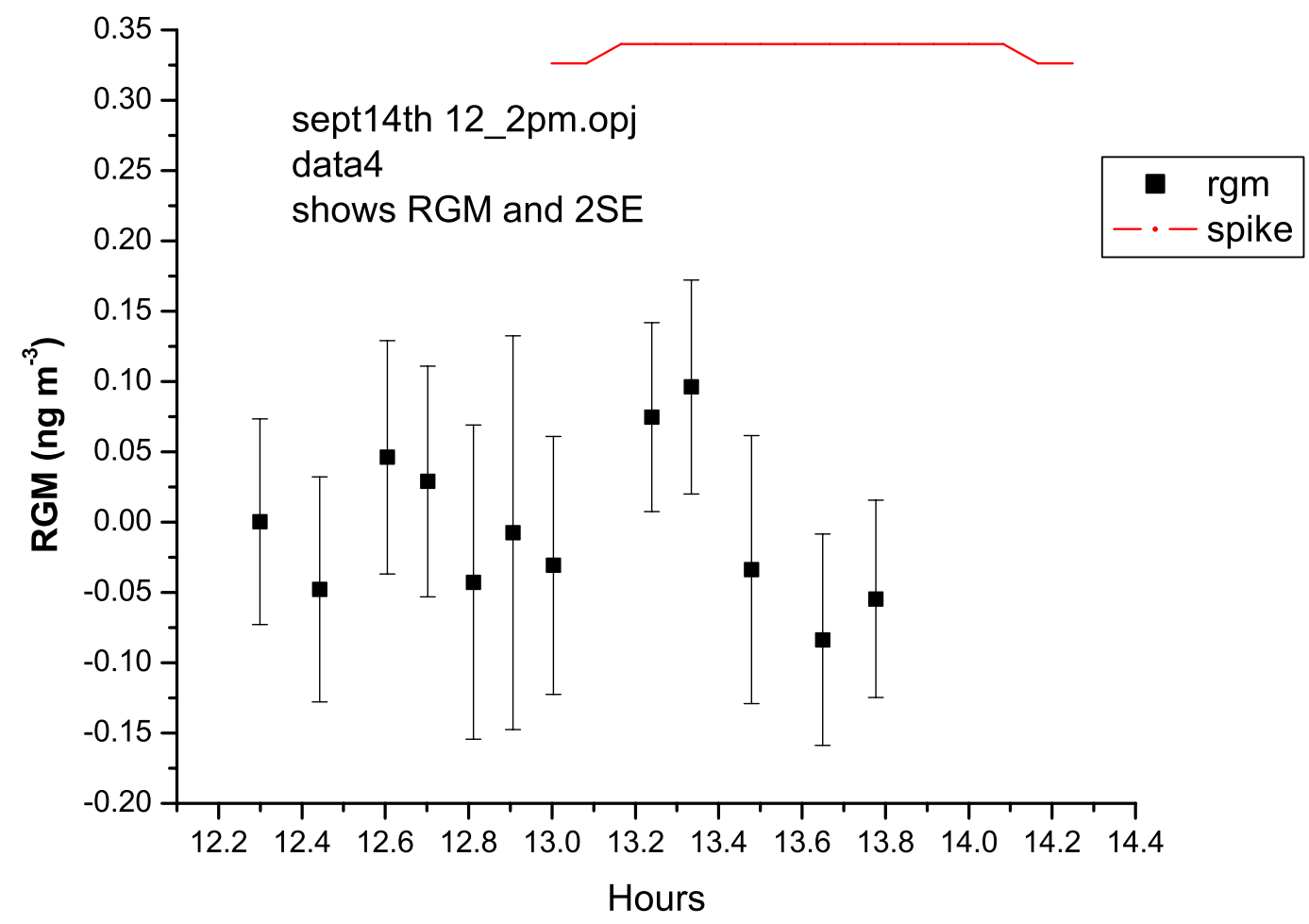

SI Figure 9: September 14 measurements 12-2pm. The RGM concentration obtained from the difference between the pyrolyzed and ambient $\mathrm{Hg}(0)$ concentrations is shown. The error bars show 2 standard errors. 


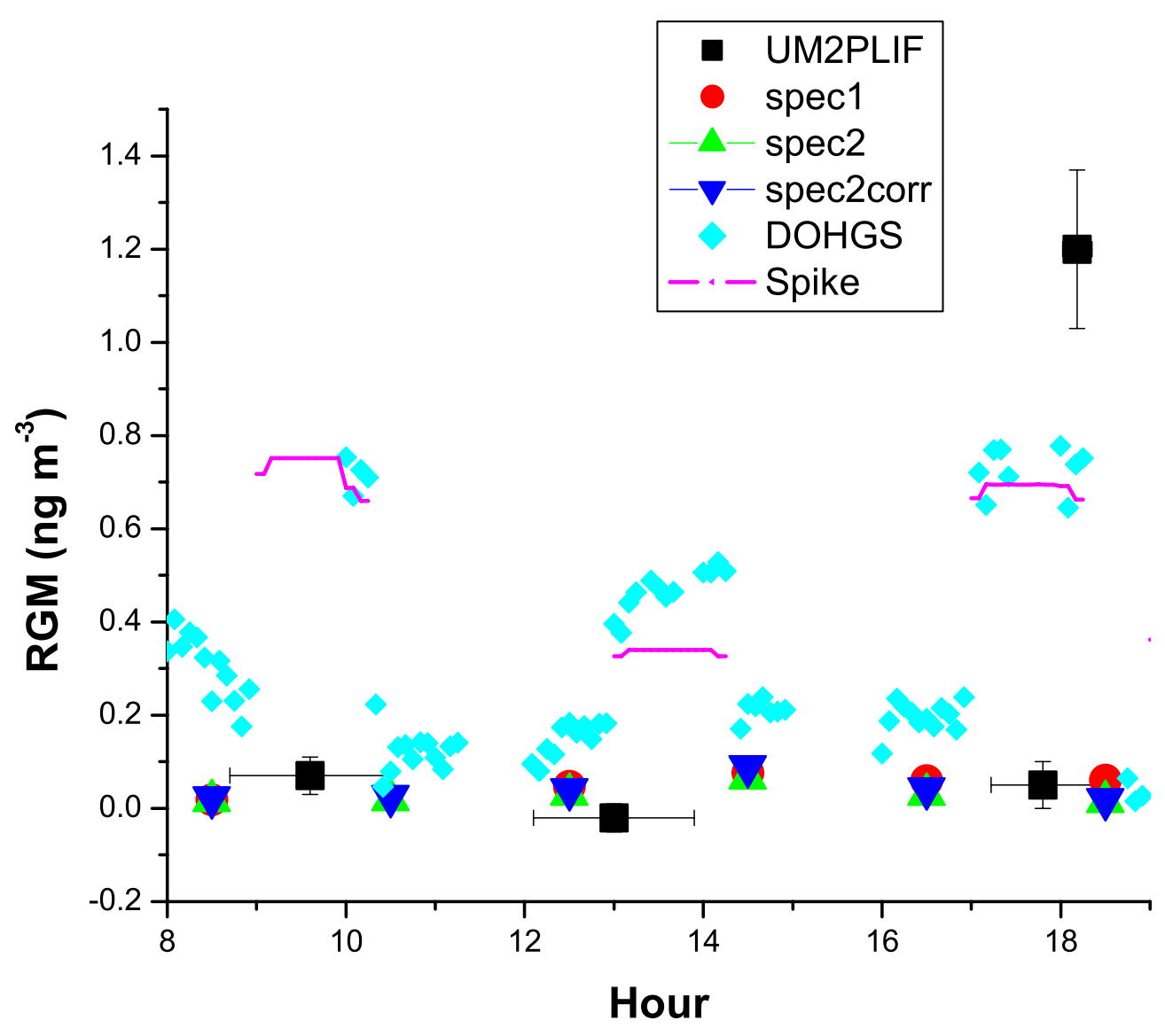

SI Figure 10: September 14 measurements: hour 8-19. The means of the 2P-LIF measurements are shown. The $\mathrm{x}$-axis error bar shows the sample time. The y-error bar is 2SE of the mean. The measurements for the UNR speciation units spec 1 and spec 2 show the sum of gaseous and particle bound oxidized mercury. The values of Spec 2 using the correction suggested by Gustin et al. (2013) are also shown. The spike concentrations were reported by the UW manifold team. The DOHGS concentrations are 5 minute averages. 


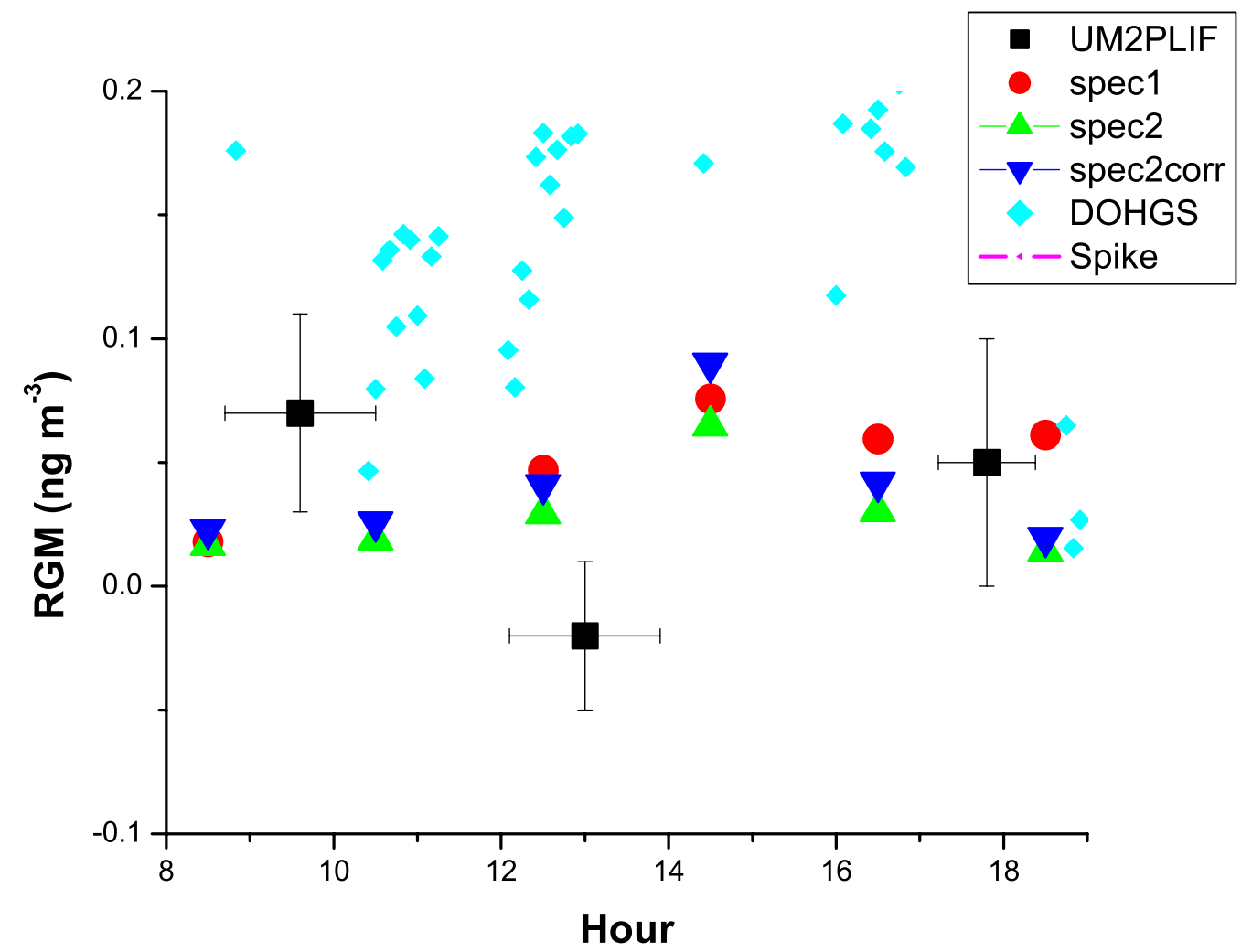

SI Figure 11. Data from SI Figure 10 plotted with an expanded concentration scale 


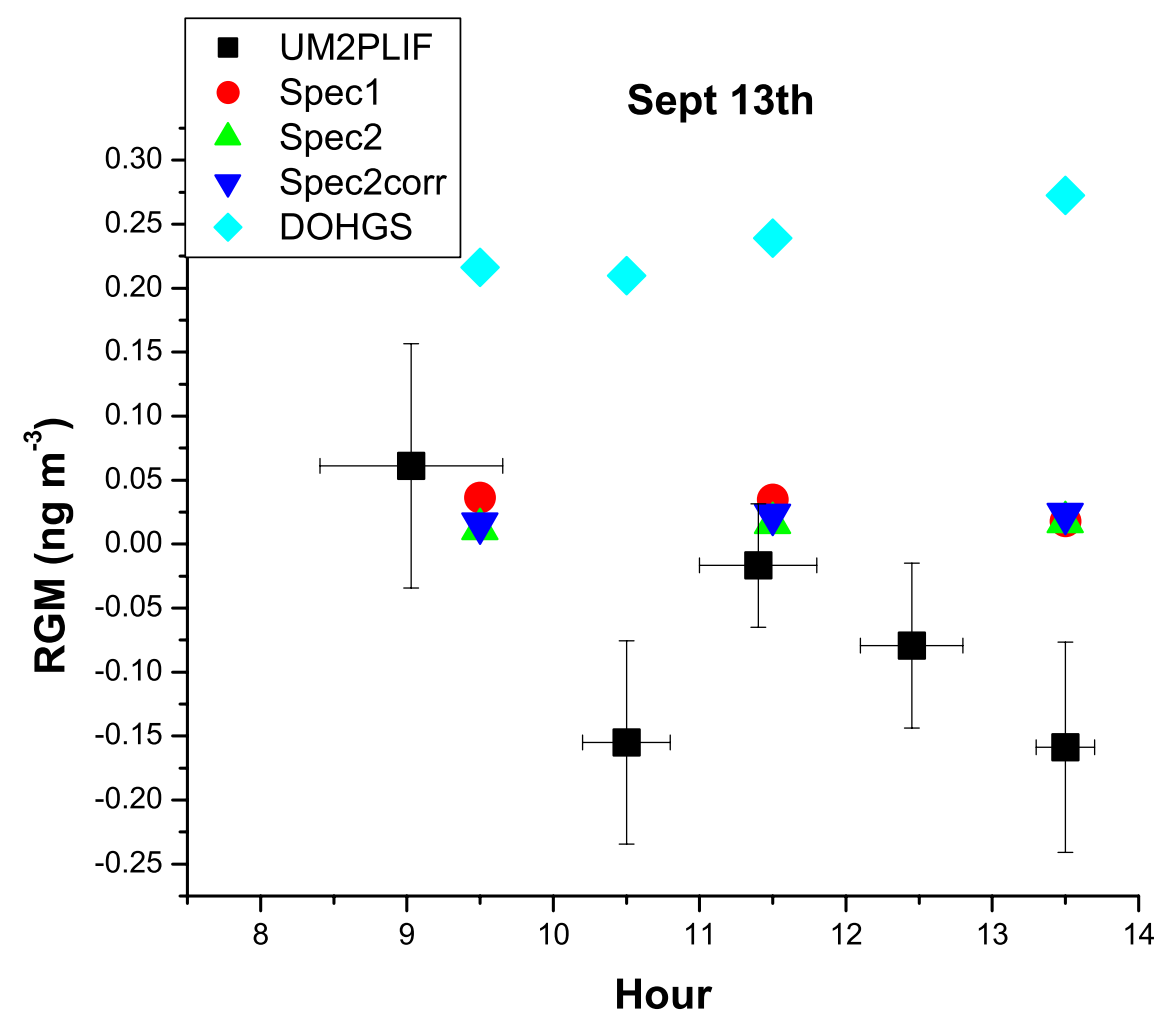

SI Figure 12: September 13 measurements: hour 8-14. The means of the 2P-LIF measurements are shown. The $\mathrm{x}$-axis error bar shows the sample time. The y-error bar is 2SE of the mean. The measurements for the UNR speciation units spec 1 and spec 2 show the sum of gaseous and particle bound oxidized mercury. The values of Spec 2 using the correction suggested by Gustin et al. (2013) are also shown. The DOHGS concentrations are hourly averages. 


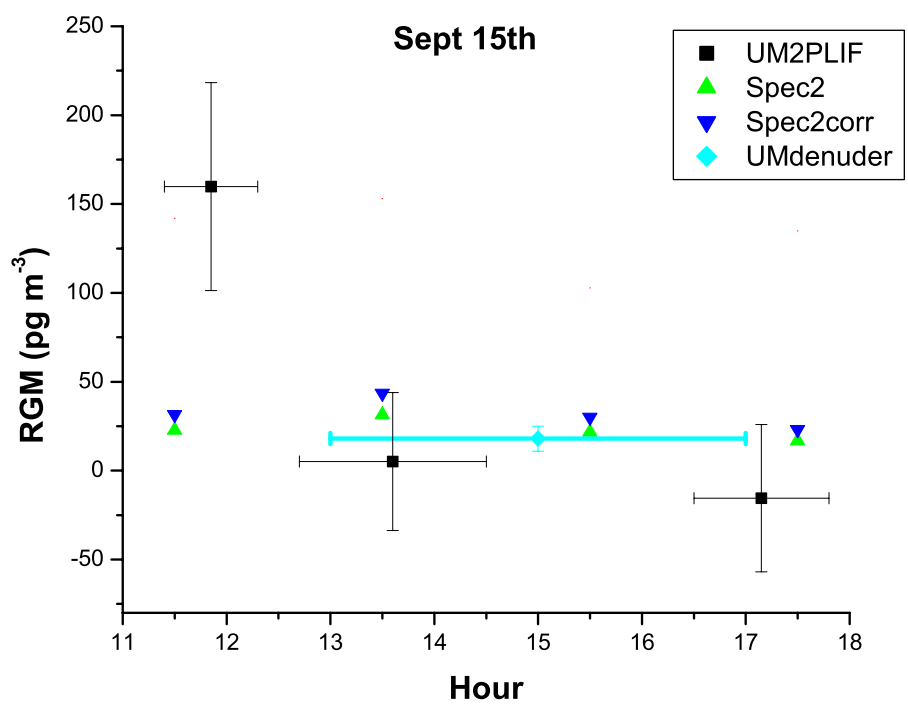

SI Figure 13. September $15^{\text {th }}$ ambient measurements. Comparison of RGM as measured by the 2P-LIF pyrolysis instrument, UNR Spec 2, and our manual denuder measurement. The UW DOHGS and Spec1 systems were sampling from the RAMIX manifold with continuous $\mathrm{HgBr}_{2}$ spiking during this period. 


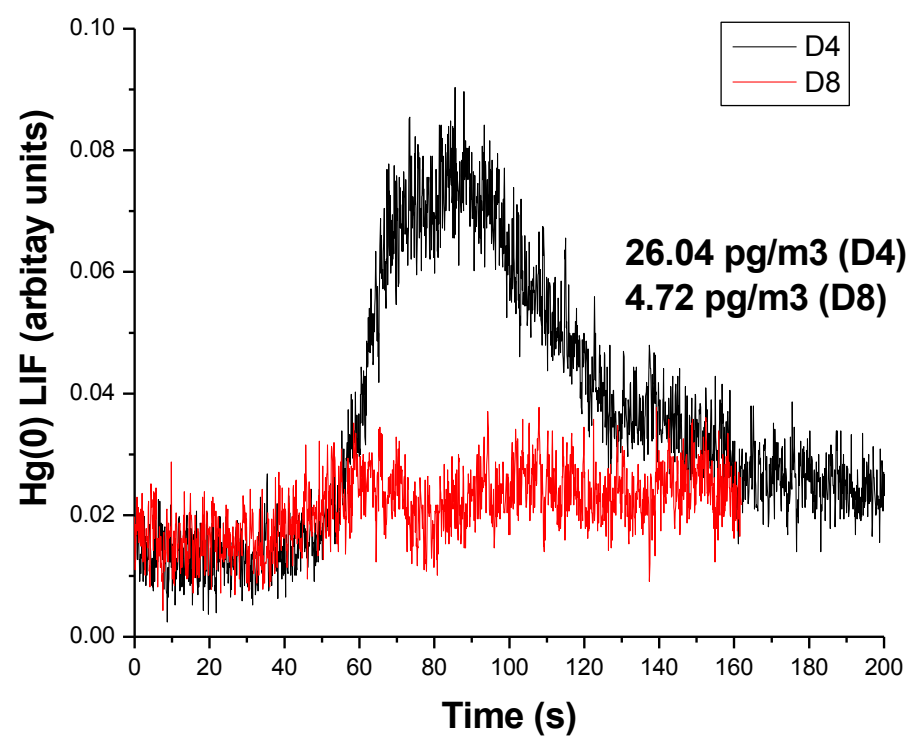

SI Figure 14: September $16^{\text {th }} \mathrm{KCl}$ manual denuder measurements. The temporal decomposition profiles (TDP) for the tandem denuder pair, D4 and D8 are shown. 


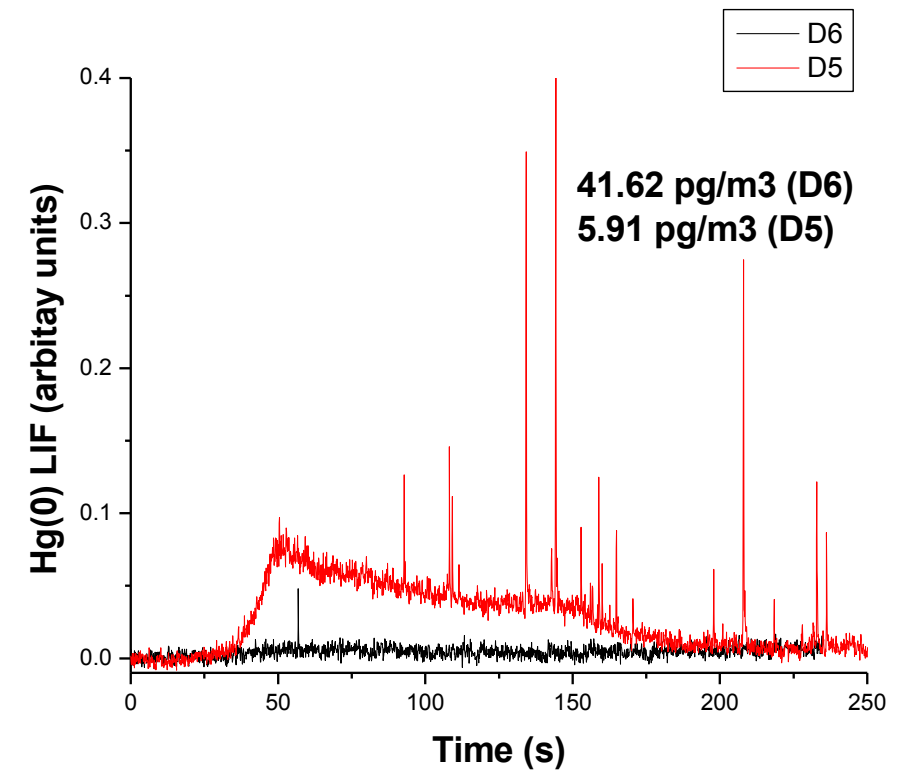

SI Figure 15: September $16^{\text {th }} \mathrm{KCl}$ manual denuder measurements. The temporal decomposition profiles (TDP) for the tandem denuder pair, D5 and D6 are shown. 


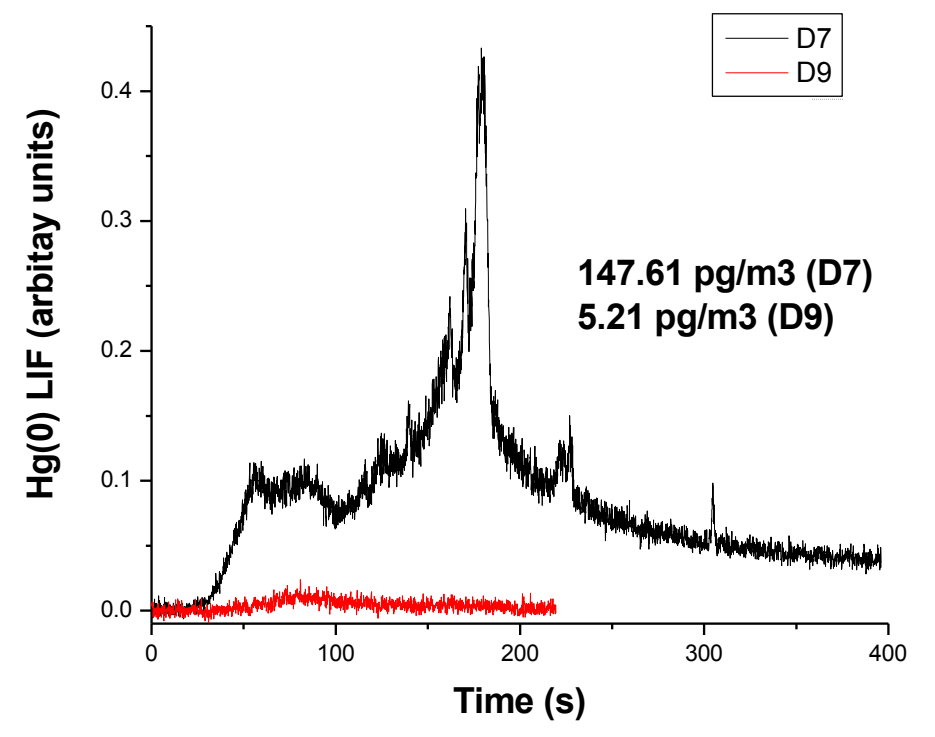

SI Figure 16: September $16^{\text {th }} \mathrm{KCl}$ manual denuder measurements. The temporal decomposition profiles (TDP) for the tandem denuder pair, D7 and D9 are shown. 